\title{
Italy chooses new brooms to clean up science institutes
}

\section{Incoming presidents expected to champion merit-based recruitment and efficiency drives.}

\section{BY EDWIN CARTLIDGE}

$\mathrm{E}$ fforts to cut nepotism and inefficiencies in Italian science may get a boost following the government's nomination of new presidents and board members for 11 of the country's public research institutes.

In a break with the past, when the government controlled the entire selection process, an independent committee of scientists has drawn up the shortlists, from which research minister Mariastella Gelmini has made the final choices. Researchers contacted by Nature say that the nominations, unveiled on 13 August, could lead to faster and more transparent recruitment and promotion throughout the institutes, as well as helping to protect science budgets from looming cuts.

Key nominations include Francesco Profumo, an electrical engineer and rector of the Polytechnic of Turin, who will replace particle physicist Luciano Maiani as president of the National Research Council (CNR). Giovanni Bignami, currently president of the international Committee on Space Research, will take over as president of the National Institute for Astrophysics (INAF), and Domenico Giardini, a seismologist at the Swiss Federal Institute of Technology in Zurich, will head the National Institute of Geophysics and Volcanology. All are due to take office next month.

The nominations are part of a broader initiative to give Italy's public research institutes greater independence, a plan that was originally proposed by the previous centreleft government of Romano Prodi and

\section{"It will not be easy to resist various pressures that seek to retain the existing structure."}

then passed into law by the current centre-right administration of Silvio Berlusconi at the end of 2009. The plan frees institutes to draw up their own statutes, and could, in principle, allow them to set up quicker and more transparent procedures for recruitment and promotion, says Italian physicist Renzo Rubele, a science-policy analyst at the Free University of Brussels in Belgium. Current procedures make it all too easy for politicians and senior scientists to advance the careers of junior researchers on the basis of personal acquaintance rather than merit.
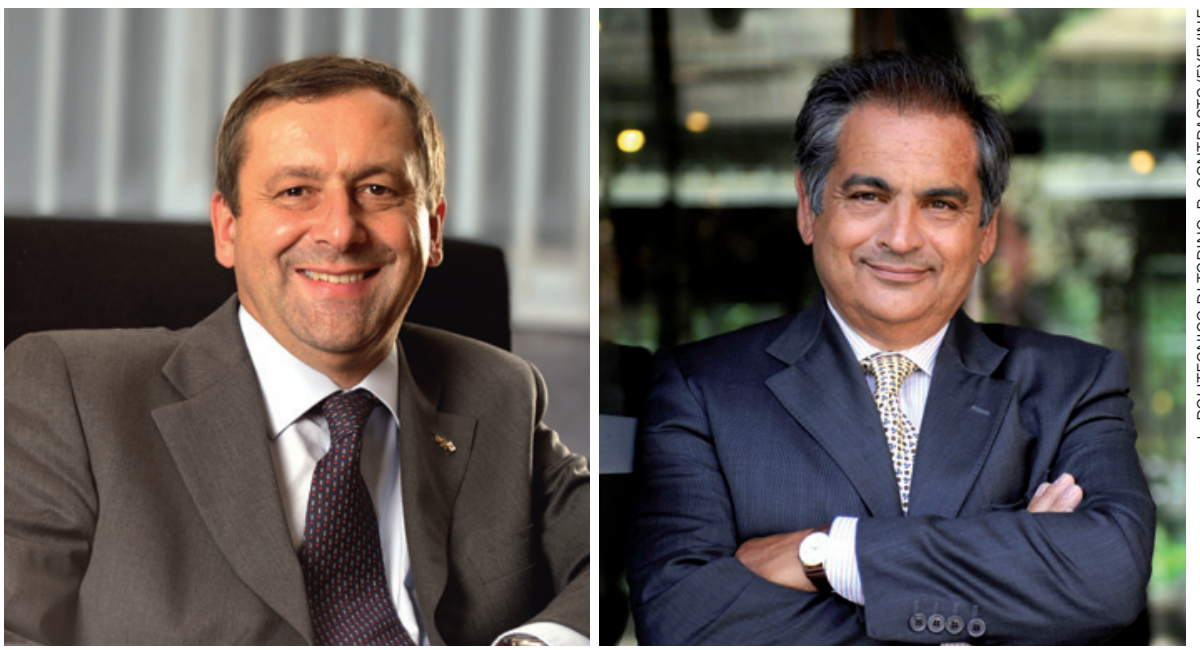

Francesco Profumo (left) and Enrico Saggese are among those slated to take over Italy's national institutes.

Political pressure is most acute at the CNR, Italy's largest research organization, which has more than 4,000 researchers working in some 100 institutes, grouped into 11 departments. Established in 2003, the departments were shaped more by politics than scientific demands, says Rubele, and their number needs to be cut. The CNR's statutes, which went into effect in May, limit the number of departments to a maximum of seven. "It will not be easy to resist various pressures that seek to retain the existing structure," says Maiani, "but the cut must be made."

That responsibility now rests with Profumo. He declined to comment on departmental restructuring, but told Nature that one priority will be to increase the organization's annual income from European programmes and industry, potentially rising from about $€ 450$ million (US\$650 million) to around $€ 1$ billion. He also thinks that CNR researchers must be encouraged to patent more of their innovations.

Although the nominations are a visible sign of greater transparency, Rubele says that there is controversy surrounding the proposed appointment of Enrico Saggese, who is slated to remain as president of the Italian Space Agency (ASI). Saggese was made president in 2009 after being installed a year earlier by the Berlusconi government as emergency $\rightarrow$ NATURE.COM

Read more on

European science policy at:

go.nature.com/ptxmzt commissioner, following the removal of the then-president, Bignami.

Saggese was previously vice-president for space activities at Finmeccanica in Rome, Italy's largest aerospace company and one of the major recipients of ASI's space procurement contracts. "ASI is often not considered scientifically as a truly independent space agency," says Rubele, "but as a means of procurement for Finmeccanica and other space-based businesses". Saggese responds that defending himself against conflict-of-interest allegations has become "boring", and argues that each president "brings his own particular experience" to the job.

Astrophysicist Pietro Ubertini of the Institute of Space Astrophysics and Cosmology in Rome, a director within the INAF, says that under the leadership of Saggese, ASI has spent a lot on applied research and not enough on pure science, but adds that at a time of great uncertainty over government funding, "it may be useful to have continuity" in the management of the agency. Saggese says, however, that ASI's funding for basic research has increased during his three years in charge, leading to a rise in both the quantity and quality of papers by Italian researchers in this field.

Rubele estimates that it will take a year to gauge the impact of the new appointees. "We will need to see what they do to the recruitment process and whether they can save their budgets from cuts," he says. "That will be a difficult exercise in the current climate." - 